\title{
Feasibility of Recycling CDW as Raw Material in Gypsum Composites
}

\author{
By Alicia San-Antonio-Gonzalez ${ }^{*}$ \\ Rocio Santos Jimenez ${ }^{\prime}$ \\ Mercedes del Rio Merino ${ }^{*}$ \\ Mariano Gonzalez Cortina ${ }^{+}$ \\ Carmen Vinas Arrebola
}

On average, Europe generates around 890 million tonnes of Construction and Demolition Waste $(C D W)$ per year and only 50\% of this $C D W$ is recycled. This is far from the objectives determined in the European Directive for 2020 and aware of this situation, the European Countries are implementing national policies to prevent the waste that can be avoidable and to promote measures to increase recycling and recovering. In Spain, one of these measures has been the development of a CDW recycling guide for the manufacture of mortar, concrete, brick and lightweight aggregates. However, there is still not enough information on the possibility of incorporating CDW materials in the manufacture of gypsum products. Therefore, the objective of this study is to analyse the feasibility of incorporating some of the most important $C D W$, which are ceramic waste and expanded polystyrene (EPS) waste, separately in a gypsum matrix. In addition, results are compared, and improvements are proposed in order to optimize the properties of the resulting materials. Results show that it is possible to incorporate up to a $50 \%$ of ceramic waste over the weight of gypsum without changing its basic properties. With this addition a $7 \%$ increase in surface hardness and a $23 \%$ reduction of capillary water absorption can be obtained. On the other hand, with the addition of EPS, a 34\% reduction of density and an $8 \%$ improvement of thermal behaviour can be obtained. All these results will be incorporated in a waste recycling database, which will be developed by the Universidad Politécnica de Madrid to help promoting the reduction of environmental impact caused by the construction sector.

\footnotetext{
${ }^{*}$ PhD Student, Technical University of Madrid, Spain ${ }^{\dagger} \mathrm{PhD}$ Student, Technical University of Madrid, Spain *Professor, Technical University of Madrid, Spain ${ }^{+}$Professor, Technical University of Madrid, Spain ${ }^{\circ}$ Technical University of Madrid, Spain
} 


\section{Introduction}

For years, specialists in solid waste management have dealt only with waste generated by household, commercial and industrial sectors, while the safe and efficient treatment of waste from construction and demolition industry has been ignored. However, each year in Europe 890 million tonnes of CDW are generated, representing up to $49 \%$ of all waste generated in the European Union (EU) (Almut et al., 2008). From these CDW, on average, 50\% are recycled (excluding land without hazardous substances), a percentage that is far from the objectives set by the European Directive 2020 (European Parliament, 2009).

In Spain, this situation is more severe. Spain not only generates more CDW than the average of the European countries, despite in the last years the situation has changed due to the serious crisis concerning the building sector, but it is also among the countries with the lowest recycling rate together with Cyprus, Poland and the Czech Republic, with a recycling rate of less than $40 \%$. In fact, the first National CDW Management Plan (Spanish Government, 2001), established the generation of waste in Spain in 47 million tonnes, from which only $13,6 \%$ were recycled, which at the same time meant that the objectives set in this Plan were not accomplished.

Because of this circumstances, the Spanish government has created several rules focused on minimizing the environmental impact caused by the construction industry and, in particular, a specific standard for the proper management of the CDW (Royal Decree 105/2008) (Spanish Government, 2008), which aims to promote their reduction and avoid landfilling, promoting as well the correct waste management to turn them into resources and save raw materials. However, currently there are no regulations in Spain considering the reuse of CDW. Only the EHE-2008 (Spanish Government, 2008), contemplates in its schedule 15 recommendations on the use of recycled aggregates in concrete.

Within this situation, some specialized centres have started publishing manuals about recycling waste, e.g., the "Catalogue of usable waste in construction", developed by CEDEX (2001) which analyses strategies for recycling aggregates from concrete and ceramic waste, the "Construction and demolition waste guide recycling and re-use across the supply chain" (Australian Government, 2012), which establishes strategies for the use of crushed concrete and brick in low-grade roads and in pavement sub-bases or the "Construction \& Demolition Waste Manual" (NYC Department of Design \& Construction, 2003), which classifies the CDW in categories according to the possibility to recycle them. However, the information in these manuals is still insufficient as none of them establishes strategies for recycling waste in gypsum composites.

All this has generated interest among researchers in the sector, which has led to the publication of numerous research works studying the feasibility of incorporating CDW in different building materials. For example, there are several works studying the use of CDW, such as paper (Klock and Aicher, 
2005), expanded polystyrene (González Madariaga, 2008), polyurethane foam (Gutierrez-Gonzalez et al., 2012), gypsum boards (Fujita, Komatsu and Kawai, 2006) or rubber (Jiménez Rivero, Guzmán Báez and García Navarro, 2014) in gypsum composites.

The Universidad Politécnica de Madrid is developing a database with different strategies for recycling waste in gypsum composites, such as rice husk (Leiva and del Río, 2013), loofah (García Hilario, 2011), feathers (Arvelo Reynoso, 2011), mussel shell (García Figuereo, 2011) or nutshell (Marte Rosario, 2011), and for CDW they are studying three different research directions: reinforcement, by incorporating mineral fibres (Romaniega, del Río and San Antonio 2013), surface hardness improvement and density reduction.

One of the most generated waste in construction sector is ceramic waste, which has been incorporated in lime mortars (González Cortina and Villanueva, 2000), alkaline cements (Puertas et al., 2006), cement mortars (Chiara and Saccani, 2011) and concrete (Medina et al., 2011), but none of these studies indicates possible applications for such materials. Besides, there are no studies analysing the feasibility of incorporating such waste into gypsum composites.

Furthermore, the use of polymers has been widely studied to reduce density, and a polymer that can be highlighted by its low density is EPS, which is used in packaging industry and as an insulation material. EPS waste has been incorporated in gypsum composites along with cardboard for the production of gypsum boards (González Madariaga, 2008). Moreover, there are more studies analysing the use of raw EPS incorporated in gypsum composites with other additives (del Río et al., 1998) and (García Santos, 2009). However, there are no studies analysing the feasibility of incorporating EPS waste in gypsum composites, other than for its use in the manufacture of gypsum boards.

For all this, the aim of this study is to analyse the feasibility of incorporating: (A) ceramic waste to increase surface hardness and (B) waste EPS to reduce density, in a gypsum matrix. Results of this study will be incorporated into the database that is being developed at the Universidad Politécnica de Madrid.

\section{Methodology}

Several series of samples were analysed composed by Plaster E-30 with ceramic wastes (ceramic waste from bricks and ceramic waste from tiles) and waste EPS with Gypsum A1. Different particle sizes and percentages of these aggregates (ceramic and EPS waste) were selected in order to study the feasibility of incorporating these CDW in a gypsum matrix.

All samples were characterised by their density in dry state, their flexural and compressive strength after 7 days and their Shore $C$ surface hardness as specified in the European Standards EN 13279-2 (AENOR, 2006) and UNE 102039 (AENOR, 1985). Furthermore, capillary water absorption was tested in composites with ceramic waste, according to European Standard EN 4592:2001 (AENOR, 2001) and thermal conductivity was tested in composites 
with waste EPS. To this end, prismatic specimens $(160 \times 40 \times 40) \mathrm{mm}^{3}$ were elaborated for each composite and previously tested to establish their water/binder (W/B) ratio according to European Standard EN 13279-2 (AENOR, 2006).

Flexural strength was determined by the load needed to break prismatic specimens supported on rollers positioned at $100 \mathrm{~mm}$ intervals. Compressive strength was determined by the load needed to break the broken sections of the specimens previously tested to flexural failure and Shore C hardness was determined by establishing the indent left by an exerted force on each test specimen, measured in Shore C units, from 0 (softest) to 100 (hardest).

Furthermore, capillary water absorption is determined by the maximum admissible load needed to separate a metal disk attached to the gypsum and thermal conductivity was measured in a laboratory tester by determining the heat flux produced by a constant heat source inside the tester through a specimen located in one of its sides.

Figure 1. Section of Prismatic Samples with Waste EPS (Right) and Ceramic Waste (Left)
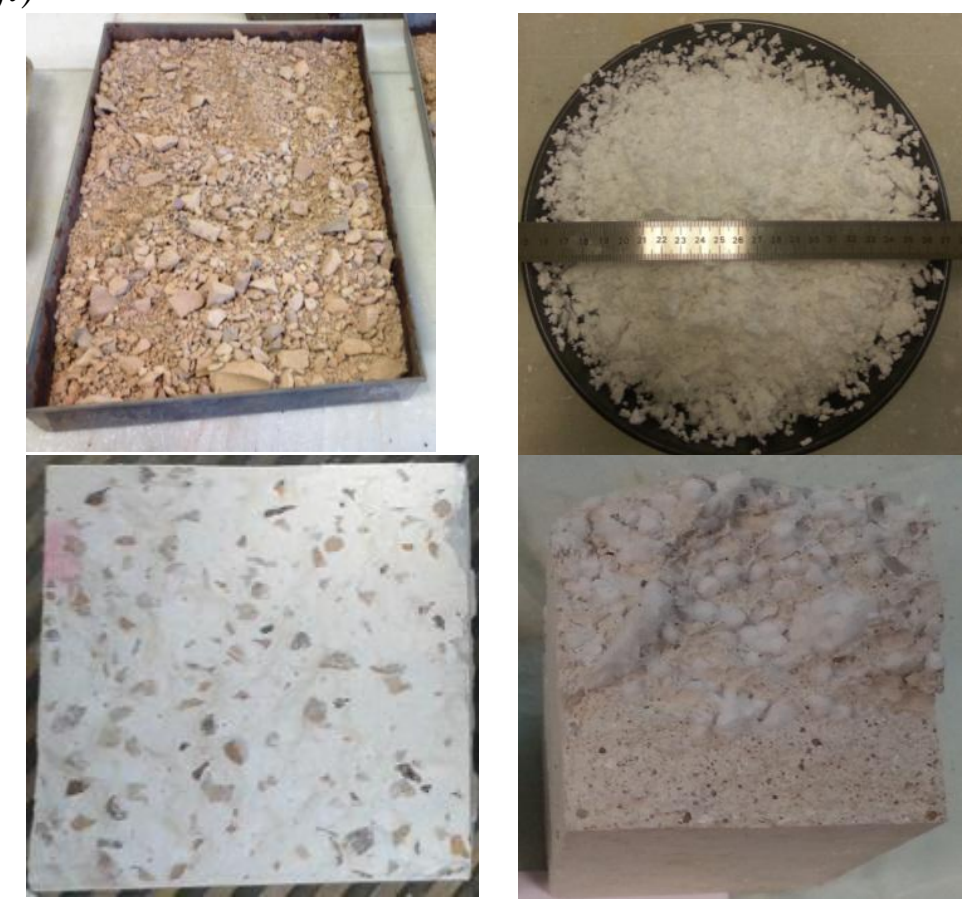

Finally, all test results were all analysed in comparison to a reference value obtained with samples prepared without any additives.

\section{Results and Discussion}

\section{Test Composites' Selection}

The experimental work was divided into three sections, tests A1, A2 and $\mathrm{B}$, according to the different type of waste incorporated into the gypsum 
composite. For each section, different composites have been selected according to particle size and percentage of waste incorporated, resulting in a total of 18 composites and 3 reference samples (Table 1).

Table 1. Test Composites

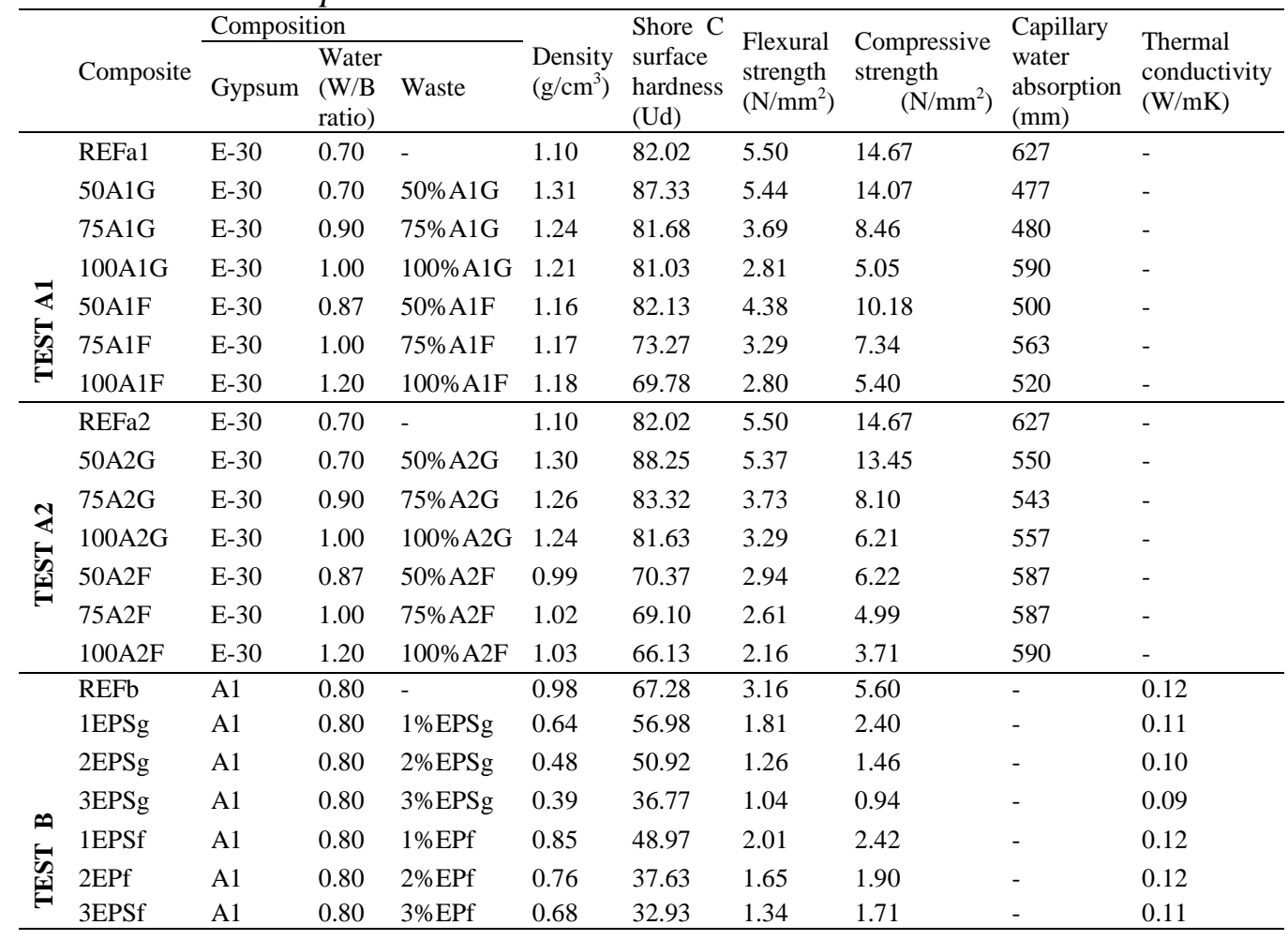

TESTS A1: Gypsum Plaster E-30 with Ceramic Waste from Bricks

The analysis of the results obtained for the composites with coarse/fine ceramic waste from bricks in different percentages of addition $(25,50$ and $100 \%$ by weight of gypsum) in comparison to the reference value REFa, shows an increase in density of up to $19 \%$, a flexural strength reduction of $1 \%$, a compressive strength reduction of $4 \%$, an increase of Shore $\mathrm{C}$ surface hardness of up to $6 \%$ and a reduction of capillary water absorption of up to $23 \%$. In general, best results are obtained with the composite 50A1G (Figure 2). 
Figure 2. Percentage of Density, Shore C Surface Hardness, Capillary Water Absorption and Mechanical Strength of Gypsum Composites with Ceramic Waste from Bricks (A1), in Comparison to the Reference Composite without Additives (REFa)

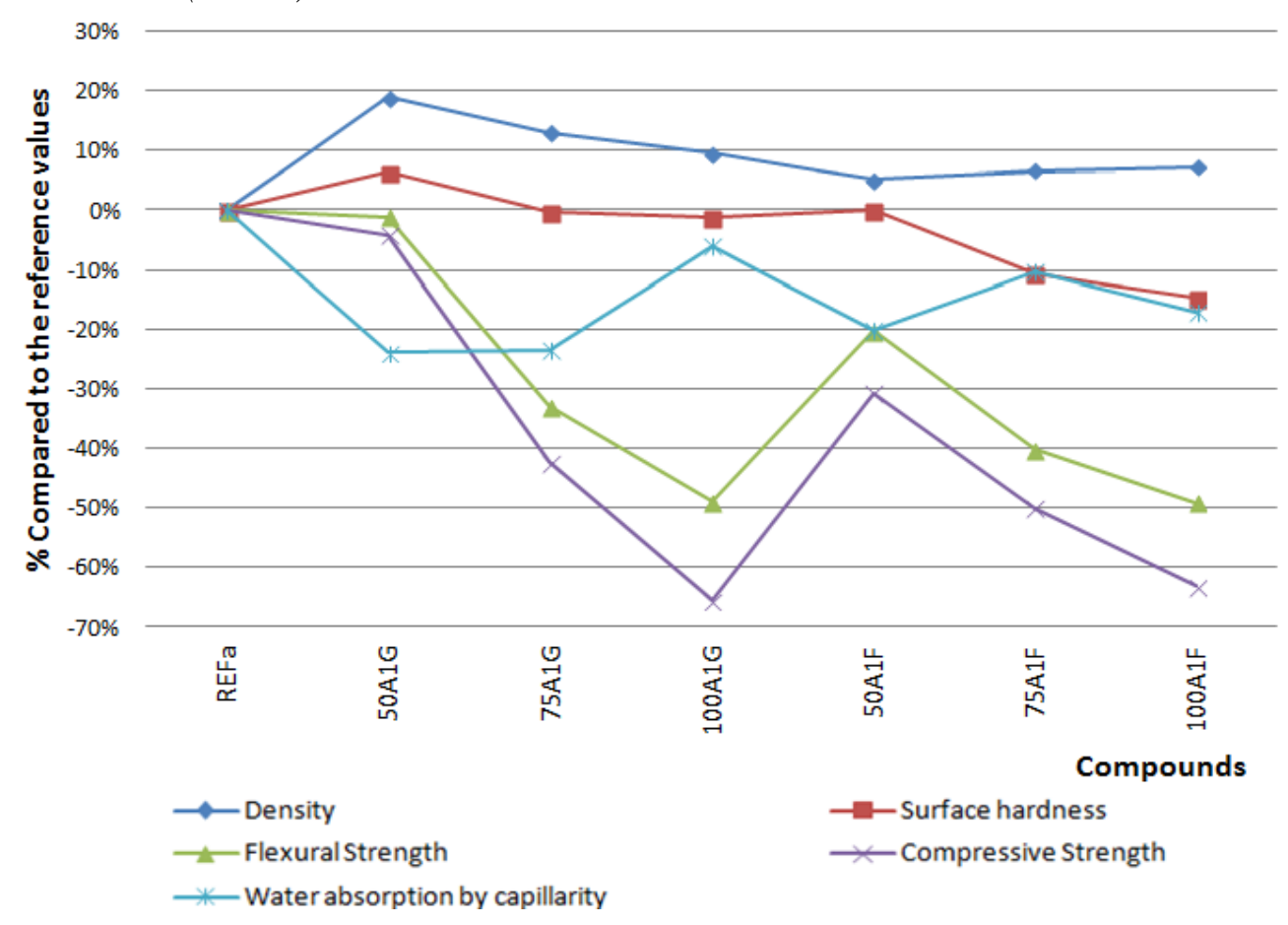

Considering the supplementary regulation RP 35.00, for gypsum plaster E30 , it is determined that minimum flexural strength is $3 \mathrm{~N} / \mathrm{mm}^{2}$ and only composites containing up to $75 \%$ of coarse aggregate satisfy this restriction (AENOR, 2009). Furthermore, the current regulation UNE-EN 13279-2 determines that compressive strength should be higher than $2 \mathrm{~N} / \mathrm{mm}^{2}$ and all composites satisfy this restriction (AENOR, 2006).

\section{TEST A2: Gypsum Plaster E-30 with Ceramic Waste from Tiles}

The analysis of the results obtained for the composites with coarse/fine ceramic waste from tiles in different percentages of addition (25, 50 and 100\% by weight of gypsum in comparison to the reference value REFb, shows an increase in density of up to $18 \%$, a flexural strength reduction of $2 \%$, compressive strength reduction of $8 \%$, an increase of Shore $\mathrm{C}$ surface hardness of $7 \%$ and a decrease of capillary water absorption of up to $13 \%$. In general, best results are obtained with the composite 50A2G (Figure 3). 
Figure 3. Percentage of Density, Shore C Surface Hardness, Capillary Water Absorption and Mechanical Strength of Gypsum Composites with Ceramic Waste from Tiles (A2), in Comparison to the Reference Composite without Additions (REFb)

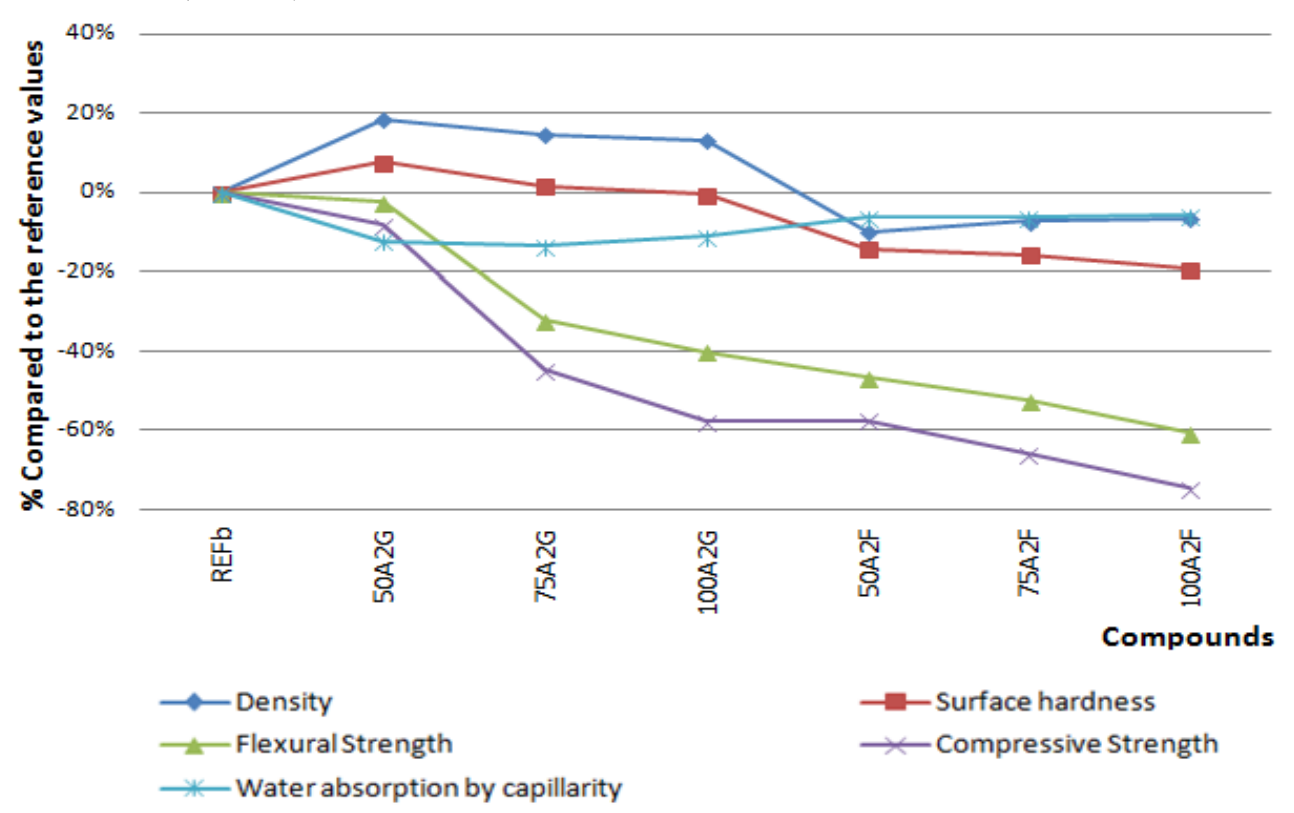

Considering the supplementary regulation RP 35.00, for Gypsum plaster E-30, it is determined that minimum flexural strength is $3 \mathrm{~N} / \mathrm{mm}^{2}$ and only composites containing up to $75 \%$ of coarse aggregate satisfy this restriction (AENOR, 2009). Furthermore, the current regulation UNE-EN 13279-2 determines that compressive strength should be higher than $2 \mathrm{~N} / \mathrm{mm}^{2}$ and all composites satisfy this restriction (AENOR, 2006).

\section{TEST B: Gypsum Al with EPS Waste}

The analysis of the results obtained for the composites with coarse/fine EPS waste in different percentages of addition (1,2 and 3\% by gypsum weight) in comparison to the reference value REFc, shows a maximum density decrease of $60 \%$, a maximum Shore C surface hardness decrease of $51 \%$, a maximum flexural strength decrease of $67 \%$, a maximum compressive strength decrease of $83 \%$ and a maximum thermal conductivity decrease of $25 \%$ (Figure 4). 
Figure 4. Percentage of Density, Shore C Surface Hardness, Thermal Conductivity and Mechanical Strength of Gypsum Composites with EPS Waste (A3), in Comparison to the Reference Composite without Additions (REFc)

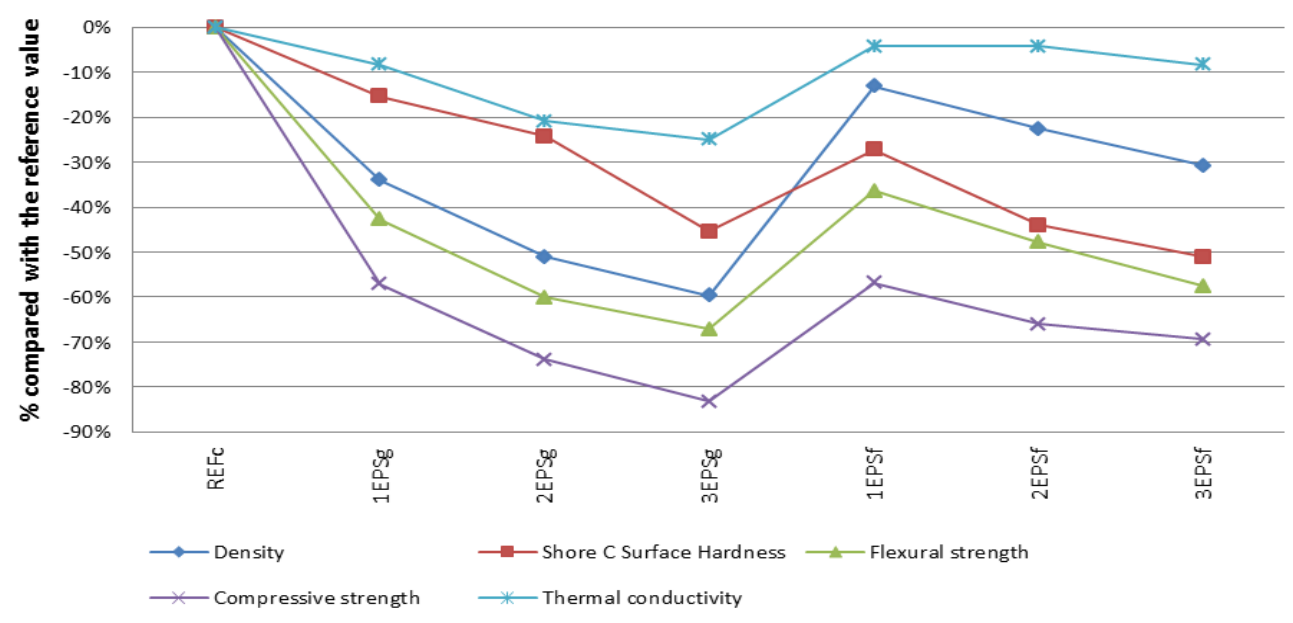

Considering the supplementary regulation RP 35.03 for lightened gypsum composites (AENOR, 2009) and UNE-EN 13279-2 (AENOR, 2006), it is determined that minimum flexural strength has to be up to $1 \mathrm{~N} / \mathrm{mm}^{2}$ and minimum compressive strength has to be up to $2 \mathrm{~N} / \mathrm{mm}^{2}$. Only composites containing $1 \%$ of coarse/fine EPS waste meet all these requirements.

Summary of the Best Results for its Application in Construction Industry

After analysing the results of all studies performed with different kinds of CDW, a summary table (Table 2) with the best composites obtained is presented, showing possible applications in the construction industry.

Table 1. Best Results and Possible Applications

\begin{tabular}{|c|c|c|c|c|c|c|c|c|c|c|}
\hline \multicolumn{4}{|c|}{ Composites composition } & \multicolumn{6}{|c|}{ Test results } & \multirow[b]{2}{*}{$\begin{array}{l}\text { Possible } \\
\text { applications }\end{array}$} \\
\hline 完 & 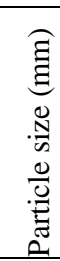 & 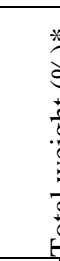 & & 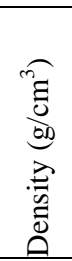 & 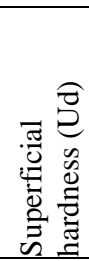 & 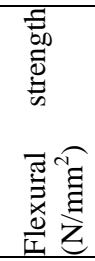 & 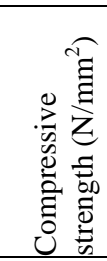 & 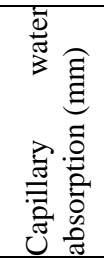 & 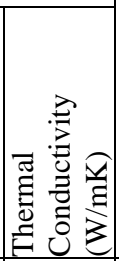 & \\
\hline \multirow{2}{*}{$\begin{array}{l}\text { Ceramic } \\
\text { waste } \\
\text { f/bricks }\end{array}$} & 2.0 & 35 & \multirow{2}{*}{50} & \multirow{2}{*}{1.31} & \multirow{2}{*}{87.33} & \multirow{2}{*}{5.44} & \multirow{2}{*}{14.07} & \multirow{2}{*}{477} & \multirow{2}{*}{ - } & $\begin{array}{l}\text { Prefabricated } \\
\text { gypsum pieces }\end{array}$ \\
\hline & 1.0 & 15 & & & & & & & & $\begin{array}{l}\text { Interior } \\
\text { cladding walls }\end{array}$ \\
\hline \multirow{2}{*}{$\begin{array}{l}\text { Ceramic } \\
\text { waste } \mathrm{f} / \mathrm{tiles}\end{array}$} & 2.0 & 35 & \multirow{2}{*}{50} & \multirow{2}{*}{1.30} & \multirow{2}{*}{88.25} & \multirow{2}{*}{5.37} & \multirow{2}{*}{13.45} & \multirow{2}{*}{550} & \multirow{2}{*}{ - } & $\begin{array}{l}\text { Prefabricated } \\
\text { gypsum pieces }\end{array}$ \\
\hline & 1.0 & 15 & & & & & & & & $\begin{array}{l}\text { Interior } \\
\text { cladding walls }\end{array}$ \\
\hline EPS waste & $4-6$ & 1 & 1 & 0.64 & 56.98 & 1.81 & 2.40 & - & 0.11 & $\begin{array}{l}\text { Prefabricated } \\
\text { gypsum pieces }\end{array}$ \\
\hline
\end{tabular}

* Rate by weight binder 


\section{Conclusions}

After analysing all the results and taking into account the minimum requirements set in the regulations, it is concluded that the proposed methodology for the preparation of gypsum composites with CDW has obtained positive results because it is possible to incorporate ceramic and EPS waste, separately, in a gypsum matrix.

Considering the limits set by the regulations, it can be concluded that is feasible to use gypsum plaster E-30 with a 50\% of ceramic waste from bricks or tiles in order to produce prefabricated gypsum and also a material for interior cladding walls. This material not only meets the minimum requirements established by current legislation related to mechanical strength; it also increases Shore $\mathrm{C}$ surface hardness a $7 \%$ and decreases the capillary water absorption up to $23 \%$.

Moreover, referring to composites with EPS waste, it can be concluded that it is feasible to use EPS waste to reduce density of gypsum composites. The maximum density reduction that can be achieved by incorporating this waste is about $34 \%$ by incorporating $1 \%$ of EPS waste with coarse particle size. Greater density reductions are feasible by adding higher percentages of waste, but this would require adding additives to improve compressive strength. This material not only meets the minimum requirements established by current legislation related to mechanical strength; it also increases thermal conductivity an $8 \%$.

\section{References}

AENOR. UNE-EN 13279-1, Gypsum binders and gypsum plasters - Part 1: Definitions and requirements. Madrid, 2009.

AENOR. UNE-EN 13279-2, Gypsum binders and gypsum plasters - Part 2: Test methods. Madrid, 2006.

AENOR. RP 35.00, Supplementary Regulations AENOR for gypsum binders and gypsum plasters, precast and other related products. Common requirements. Madrid, 2009.

AENOR. RP 35.03, Supplementary Regulations AENOR for gypsum binders and gypsum plasters, precast and other related products. Lightened gypsum. Madrid, 2009.

AENOR. UNE 102039, Gypsum binders and gypsum plasters. Shore C and Brinell hardness determination. Madrid, 1985.

AENOR. UNE EN 459-2:2001, Determination of water retention. Madrid, 2001.

Almut R., et al. EU as a Recycling Society, Present recycling levels of Municipal Waste and Construction \& Demolition Waste in the EU. European Topic Centre on Sustainable Consumption and Production. Denmark, 2008.

Arvelo Reynoso, ED. Use of feathers to improve toughness in mortars. Master's Degree Final Project, Universidad Politécnica de Madrid, 2011.

Australian Government. Construction and demolition waste guide recycling and re-use across the supply chain. Australia, 2012.

CEDEX. Catalogue of usable waste in construction. Madrid, 2001. 
Chiara Bignozzi, M.; Saccani, A. "Ceramic waste as aggregate and supplementary cementing material: A combined action to contrast alkali silica reaction (ASR)". Cement \& Concrete Composites; 2011:34:1141-1148.

Del Río Merino M., et al. "Elaboración y aplicaciones constructivas de paneles prefabricados de escayola aligerada y reforzada con fibras de vidrio e y otros aditivos. (Elaboration and constructive applications of prefabricated plasterboards systems of lightweight plaster and fiber reinforced glass or other additives). Universidad Politécnica de Madrid, Madrid, 1998.

European Parliament. Directive 2009/28/EC, promotion of the use of energy from renewable sources. European Union, 2009.

Fujita, T.; Komatsu, N.; Kawai, S.A. Manufacture and properties of gypsum-bonded particleboard IV. Properties of gypsum-bonded particleboard made with raw material from waste gypsum boards. Mokuzai gakkaishi; 2006:52(6):368-375.

García Figuereo, J.A. The addition of shell mussels in plaster, lime and cement composites. Master's Degree Final Project, Universidad Politécnica de Madrid, 2011.

García Hilario, A. Incorporation of loofah in plaster. Master's Degree Final Project, Universidad Politécnica de Madrid, 2011.

García Santos A. Plaster reinforced with polypropylene fiber and lightened with expanded polystyrene beads. Materiales de Construcción; 2009:59:105-124.

González Cortina, M.; Villanueva domínguez, L. "Recovery of roman mortars made with lime and ceramic waste in current applications". Universidad Politécnica de Madrid, 2000.

González Madariaga, F.J. Mixtures of waste expanded polystyrene (EPS) with gypsum or gypsum plaster for use in construction. Informes de la Construcción; 2008:60:35- 43.

Gutierrez-Gonzalez, S.; Gadea, J.; Rodriguez, A.; Junco, C.; Calderon, V. Lightweight gypsum materials with enhanced thermal properties made with polyurethane foam wastes. Construction and Building Materials; 2012.

Jiménez Rivero, A.; de Guzmán Báez, A.; García Navarro, J. New composite gypsum - ground waste rubber coming from pipe foam insulation. Construction and Building Materials; 2014:55:146-152.

Klock, W.; Aicher, S. Size effect in paper fiber-reinforced gypsum panels under inplane bending. Wood and Fiber Science, 2005.

Leiva Aguilera, M.J.; Del Río Merino M. "Additived gypsum with rice husk waste”. I International and III National Congress on Sustainable Construction and Ecoefficient Solutions. Universidad de Sevilla, 20-22 May 2013.

Marte Rosario, M. Use of Chandler nutshell in plaster composites. Master's Degree Final Project, Universidad Politécnica de Madrid, 2011.

Medina, C., et al. Characterization of concrete made with recycled aggregate from ceramic sanitary ware. Materiales de Construcción; 2011:61(304):533-546.

NYC Department of Design \& Construction. "Construction \& Demolition Waste Manual" New York, 2003.

Puertas, F.; Barba, A.; Gazulla, M.F.; Gómez, M.P.; Palacio, M.; Martínez-Ramírez, S. "Ceramic wastes as raw materials in portland cement clinker fabrication: Characterization and alcaline activation". Materiales de Construcción; 2006:56(281):73-84.

Romaniega Piñeiro, S.; Del Río Merino M.; San Antonio González, A. "Gypsum reinforcement with fibers by mineral wool obtained from the recycle of construction and demolition waste". I International y III National Congress on 
Sustainable Construction and Ecoefficient Solutions. Universidad de Sevilla, May, 2013.

Spanish Government. National Plan for Construction and Demolition Waste 20012006. BOE, July 2001, n. 166, p. 25305.

Spanish Government. Real Decree 105/2008, on the production and management of construction and demolition waste. BOE, February 2008, n. 38, p. 7724.

Spanish Government. Instruction for Structural Concrete (EHE 2008). Madrid, 2008. 
